\title{
Innovative Online Vocational Training of Renewable Energy Technologies (INNOVRET)
}

\author{
A. Dimache, S. Kopeinik, A. Brennan, T. Roche, L. C. Winter, and D. Albert
}

\begin{abstract}
Heat pump systems are very important at a European level as they help meet the 20-20-20 targets of the EU policy. In recent years, the European market for these technologies has increased constantly. In addition to having insufficient numbers qualified in heat pump systems installation, current training has been recognised to have limitations. If high quality, standardised training in heat pump systems is not provided, it could result in a drawing back of the market development of heat pump systems in the EU. Furthermore, the low efficiency, poor reliability and increased cost of heat pump system installation and maintenance, which has resulted from poor training has also resulted in disillusionment on the part of the purchaser, notwithstanding the obstacles of time, cost and distance on the part of the installer with regard to training. INNOVRET (Innovative Online Vocational Training of Renewable Energy Technologies), a Leonardo da Vinci funded project, aims to address the need for training sufficient numbers in heat pump system installation throughout the EU. The innovative online training solution developed by the INNOVRET team will overcome the time, cost and distance constraints of learners through the delivery of the training in a flexible and accessible way. The methodological approach to training delivery is based on the Competence-based Knowledge Space Theory (CbKST). CbKST is a framework for representing the conceptual organisation of a given body of competences, which supports self-regulated learning. By developing competencies in the installation and maintenance of heat pump systems, installers and maintenance personnel all over Europe will be able to leverage these capabilities in order to increase their employability in the emergent heat pump system sector.
\end{abstract}

Index Terms-Online training, competence-based knowledge space theory, self-regulated learning, moodle, heat pump.

\section{INTRODUCTION}

In recognition of the need for growth, competitivity, employability and sustainability, one of the goals of the 'Europe 2020 Strategy' concerns the promotion of "a more energy and resource efficient, sustainable, low carbon, secure, interconnected and competitive Europe, to the benefit of all consumers" i.e. $20 \%$ less greenhouse gas emissions, $20 \%$ renewables in final energy consumption and $20 \%$ increase in energy efficiency [1]-[3]. Heat pump systems are a critical component of achieving such energy efficiency. Recent

Manuscript received May 30, 2013; revised September 10, 2013. This work was supported by the Leonardo da Vinci Programme.

A. Dimache, A. Brennan, and T. Roche are with the Galway-Mayo Institute of Technology, Galway, Ireland (e-mail: aurora.dimache@gmit.ie, attracta.brennan@gmit.ie, tom.roche@gmit.ie).

S. Kopeinik and L. C. Winter are with Graz University of Technology, Graz, Austria (e-mail: s.kopeinik@tugraz.at, 1.winter@tugraz.at).

D. Albert is with Graz University of Technology and University of Graz, Graz, Austria (e-mail: dietrich.albert@tugraz.at). studies show that whilst heat pumps currently cut $\mathrm{CO} 2$ emissions by $8 \%$ of global emissions [4], which is one of the largest that a single technology can offer, this will increase in the near future, because of increased efficiency due to technological developments. This is further underscored by the fact that at the end of 2011, there were 4.57 million heat pumps installed in 20 countries, with predictions showing continuous demand increases [5]. Notwithstanding this 'prediction', a condition of the EU Directive on renewable energy (RES Directive) regarding heat pumps and their role in helping member states attain a $20 \%$ share of energy from renewable sources by 2020 requires that heat pumps meet minimum performance standards [6]. The European Heat Pump Association (representing the majority of the European heat pump industry) contends that an essential component of meeting such standards is the correct installation of reliable heat pumps [7]. Whilst European training programmes in heat pump technology are currently available, they have severe limitations. A report from the UK indicated that badly installed heat pumps resulted in $87 \%$ of these systems under-performing (below a COP of 3.0) [8].

In addressing the need for high quality heat pump systems training programmes and the EU focus on life-long learning (to promote European competitivity and growth) [9], the INNOVRET (Innovative Online Vocational Training of Renewable Energy Technologies) project aims to provide an online training solution for heat pump installers comprising online learning approaches, proven and tested pedagogical models, industry validated content and a state of the art fully integrated, interactive energy laboratory.

The INNOVRET e-training programme will address the training and upskilling needs of geographically dispersed, vocational learners throughout Europe. The accessibility, flexibility and adaptability of the online solution will support competence based, self-regulated learning and will foster a broader penetration into the targeted European marketplace with the potential for certifying sufficient heat pump maintenance personnel and installers to meet predicted demands.

This paper is describing the online solution offered by INNOVRET for vocational training in heat pump systems installation. The research team is currently working on the preliminary testing of the e-training programme. Feedback is being collected and will be used in the next stage of the project, the refinement of the online solution.

\section{GAPS IN TRAining OF HeAt PUMP System INSTALLATION}

Article 14.3 of the RES Directive requires each Member State to develop certification schemes for small-scale RET 
(renewable energy technology) systems and recognise the certification awarded by other Member States in accordance with those criteria [6]. In response (and also acknowledging the problems/limitations with current non-standard heat pump training programmes), the European Heat Pump Association has developed the EUCert - a training and certification scheme - which aims to have a common, mutually accepted heat pump installer certificate in all participating countries. Currently, over 935 trained installers have trained on the EUCert [10]. Whilst there is an acknowledged need for further trained installers, statistics from the EHPA shows that the number of trainees is stagnating due to barriers of cost, time and distance [10]. As an alternative, they suggest that an online course would overcome these obstacles thereby resulting in more trained installers, more quality installations, better performances of the already efficient heat pumps and more consumer confidence in an already growing market.

In addition to having insufficient numbers qualified in heat pump systems (installation and maintenance), if high quality training in heat pump systems is not provided, it could result in a drawing back of the market development of heat pump systems in the EU. Furthermore, the low efficiency, poor reliability and increased cost of heat pump system installation and maintenance, which has resulted from poor training has also resulted in disillusionment on the part of the purchaser.

The Treaty of Lisbon - particularly article 166 [11], as well as the 2020 strategic framework for European cooperation in education and training (ET 2020) [12] have reinforced the need of vocational education and training in the acquisition and development of skills and competencies needed for employability at a European level.

To optimise training and learning, the learner needs to be provided with tools with which to interact and visualise system operation whilst supported in the analysis and evaluation of the heat pump system's performance under different loading conditions. The learner also needs to be able to interact with real system's data and learn from poor heat pump system installation and maintenance whilst studying the impact of real environmental conditions (in which the system is operating) on efficient and reliable energy generation and delivery mechanisms, using heat pumps.

A review of modern remote laboratories highlighted that whilst there is an exponential growth of demand for such laboratories to deliver an enhanced learning experience, their limitations still exceed their capabilities to deliver [13]. The overriding limitation is the need for new educational concepts, "new pedagogical and cognitive practices of learning and instruction" [14] and new learning media for this environment [15]. Another limitation of remote laboratories is the lack of coupling between the Learning Management System (LMS) and the learner's progress [13]. This gap between remote laboratories and the LMS needs to be closed for a more enriched learning experience [16]. Gravier et al. [16] also point out that whilst a remote laboratory can bring a hands-on approach to the learner, the current drawback of such laboratories concerns the ensuing social isolation.

Aside from the solar energy e-learning laboratory at the Technical University, Cyprus [15], there is very little evidence internationally for the existence of online energy laboratories, moreover online energy laboratories with access to a variety of integrated RET systems.

\section{The INNOVATIVE ONLINE TRAINING SOLUTION OFFERED BY INNOVRET}

Combining pedagogical and technical expertise, the INNOVRET project embeds a proven and tested online pedagogical model and a state of the art interactive energy laboratory in Moodle, a highly popular LMS. The resulting course is offering content which is validated by industry, a subject domain structured on the level of competences, learning objects (LOs) in conjunction with associated assessment items and Moodle plugins to support competence based, self-regulated learning (SRL). To enhance the experience, learning objects have been designed to cater to different learning styles (e.g. audio, visual, kinaesthetic). The INNOVRET model is presented in Fig. 1.

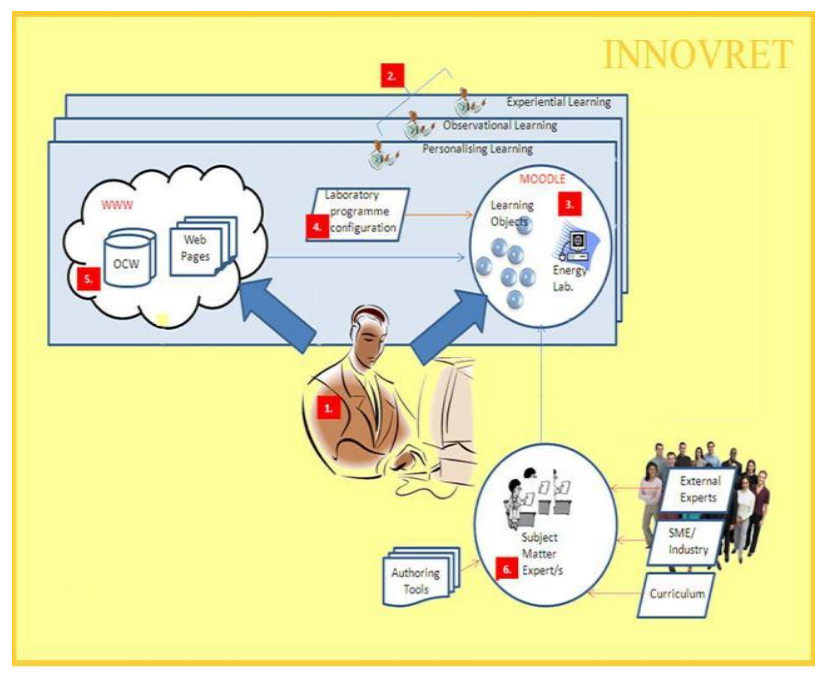

Fig. 1. The INNOVRET model.

\section{A. Pedagogical Approach}

INNOVRET's pedagogical model is based on the Competence-based Knowledge Space Theory (CbKST) in conjunction with self-regulated learning (SRL). Similar approaches have been successfully applied in EU-funded projects, such as ROLE [17] and iClass [18], [19].

The CbKST is a framework for representing the conceptual organisation of a given body of competences. The CbKST, as a cognitive approach, extends the behaviourist Knowledge Space Theory [20]-[22] and requires the identification of threshold concepts and associated pre-requisite and co-requisite relationships between competences. It also requires the creation of appropriate assessments to evaluate a learner's current competence state in said threshold concepts. Threshold concepts represent a transformed way of understanding something without which the learner would find it difficult to progress [23]. In the case of the INNOVRET model, they represent a set of competences (skills, abilities, knowledge and understanding of concepts) [19], [24], [25] which underlie the set of problems for the heat pump domain. The result of the application of CbKST is a structured competence model 
enriched with corresponding learning objects (i.e. digital content that may be used for learning, education or training [26]) and associated assessments.

Within the INNOVRET project our understanding of self-regulated learning (SRL) is in accordance with Zimmerman's definition [27]. SRL is understood as a learning cycle consisting of three phases the learner is proactively engaged with. In INNOVRET these phases are mainly caused on the three phases suggested by Zimmerman (2002) and are introduced as "planning", "learning" and "reflecting".

The main aim of the application of the CbKST in INNOVRET is the introduction of adaptivity by means of adaptive presentation of the learning content on the one hand and adaptive assessment of the learner's current competence state on the other hand. The adaptive system recommends LOs which are appropriate to a learner's competence state. The competence state has to be assessed previously (through assessment items).

INNOVRET's model aims to combine guided/personalised learning with principles of SRL. SRL takes place for instance when learners select a learning cycle's learning target (planning phase), freely navigate through the recommended LOs (learning phase) or reflect upon their last sessions learning progress. Therefore the CbKST principles are linked to the phases of self-regulated learning through the use of certain tools (see Fig. 2).

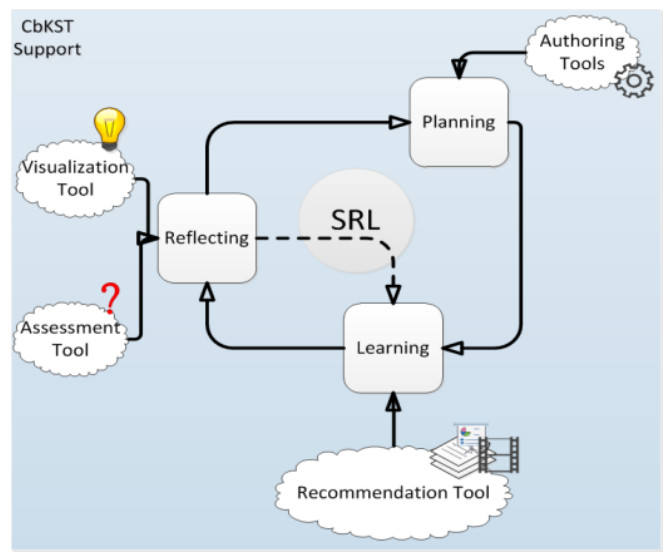

Fig. 2. Phases of SRL in INNOVRET with regard to the applied software components (authoring tool, planning tool, recommendation tool, assessment and learning progress tool).

A structured competence model enriched with corresponding Learning Objects (LOs) and Assessment Items (AIs) forms the CbKST Domain Model on which INNOVRET's SRL tools are based. Through the CbKST-based adaptive assessment, it is possible to identify a person's current competence state while presenting a reasonable number of assessment items, which spares potential learning time. Based on the assessment, the Recommendation Tool presents a collection of learning objects tailored to an individual learner's abilities (i.e. neither over- nor unchallenging) from which the learner selects in a self-regulated manner. The learning progress is again captured in an assessment and leads to a reflection stimulating learning progress visualisation.

\section{B. Moodle: the Learning Management System}

Moodle (Modular Object-Oriented Dynamic Learning
Environment) has been selected as the Learning Management System (LMS) for INNOVRET. Moodle is an open source LMS which is capable of supporting the necessary high levels of interaction, web visibility, online social networking, and knowledge exchange [28]. Moodle includes many features that improve pedagogical quality and many of the essential tools that an e-learning system should contain [29]. It provides a variety of features to support teachers and course developers to create and manage their online course, which typically includes different kinds of LOs. Moreover, Moodle has tracking features that allow the individual participant's progress to be monitored as they work through the learning module [30].

Despite all of the afore-mentioned advantages, Moodle is usually course based, and does not cater to the individual needs of students [31]. However, it is easily extendible (one of the main reasons for the choice of Moodle is its supported extensibility in terms of plug-ins and modules that can be used for adjustments to the targeted learners' needs) and is therefore an excellent platform with respect to adaptation. Although many adaptive systems based on Moodle have been developed, none of them take into account the SRL phases or the CbKST. As already outlined, services and tools based on CbKST algorithms were tailored specifically to INNOVRET's needs and embedded in Moodle. Fig. 3 shows the CbKST-based Authoring Tool which enables the educator to assign a course's learning objects and assessment items (i.e. problems) to the respective competences.

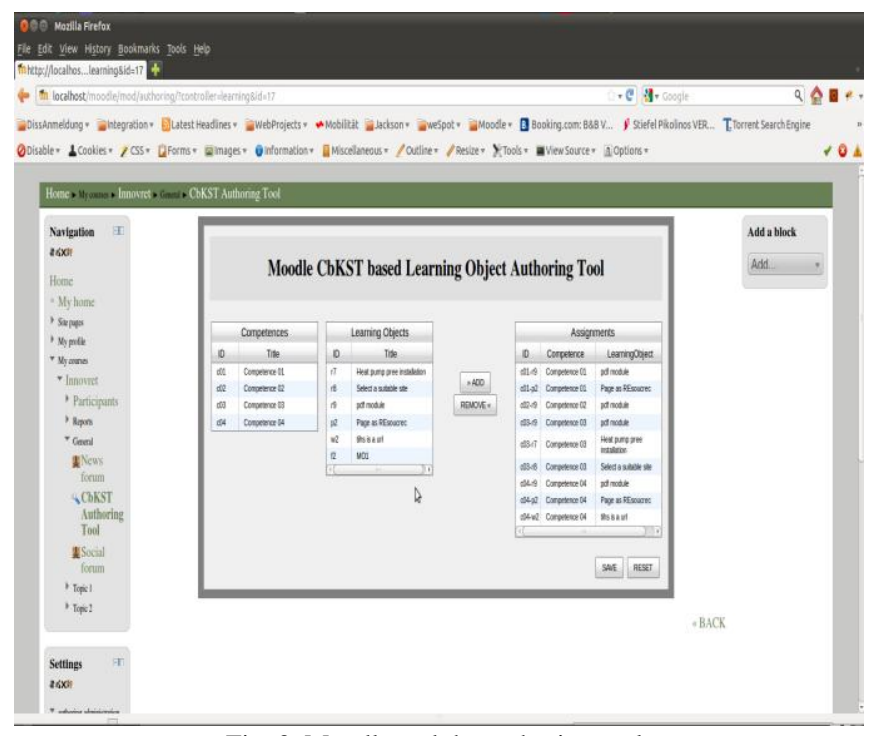

Fig. 3. Moodle and the authoring tool.

\section{The Energy Laboratory}

GMIT has installed a range of functional renewable energy systems in a new online energy laboratory. Uniquely, the students in this laboratory learn about the installation, analysis and performance of integrated, real working renewable energy systems rather than that of individual renewable energy technologies, which is critical to their effective real world deployment. Currently, in-class learners are presented with a sophisticated web enabled man machine interface which allows them to understand the construction, live operation and performance of the systems - see Fig. 4.

Further, learners are allowed to view and extract 
performance data and trends for each individual component of the system under different loading conditions, see figure 5 . A web camera has been commissioned to allow the students to view the equipment online. Renewable energy technologies in the lab include solar panels, biomass boilers, heat pumps and wind turbines. Examples of energy distribution systems include various under floor heating systems and radiator technologies.

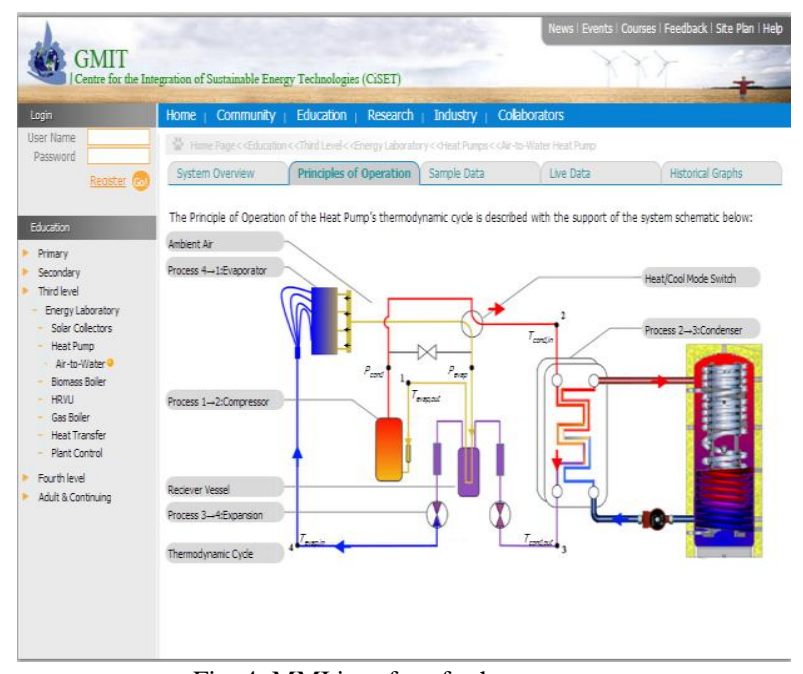

Fig. 4. MMI interface for heat pumps.
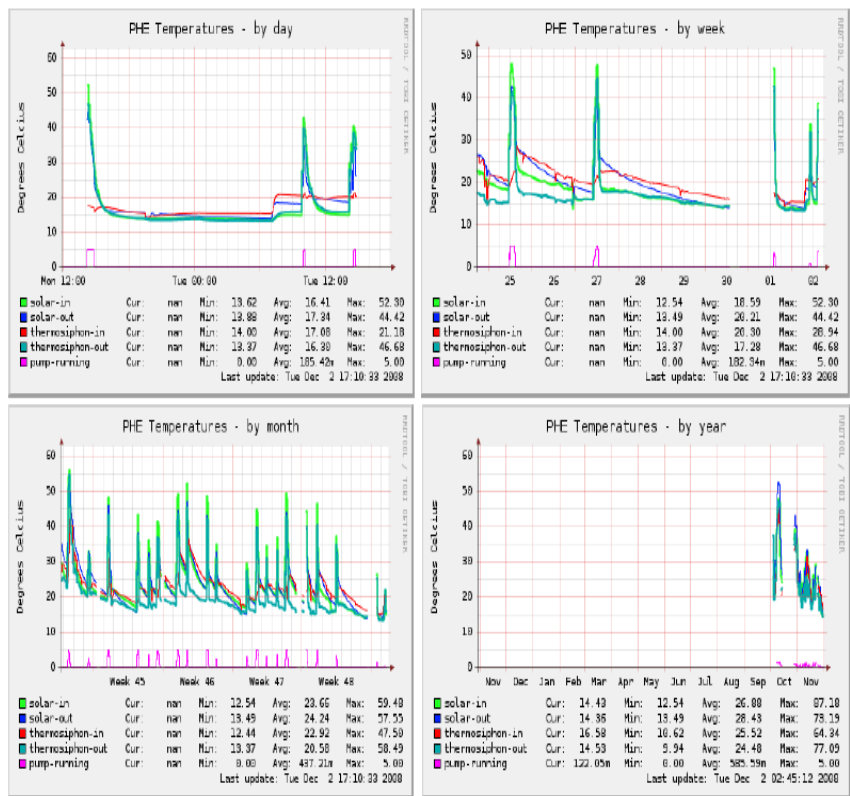

Fig. 5. Online data display from the energy lab.

The training programme offered by INNOVRET supports the learner in interacting and visualising heat pump system operation whilst also being supported in the analysis and evaluation of the heat pump system's performance under different loading conditions.

\section{CONCLUSION}

Heat pump systems are of crucial importance at a European level as they help meet the 20-20-20 targets of the EU policy. In recent years, the European market for these technologies has increased constantly. In addition to having insufficient numbers qualified in heat pump systems (installation and maintenance), current training has been recognised to have limitations.

However, through its innovative e-training programme, INNOVRET aims to address the need for training sufficient numbers in heat pump systems throughout the EU. It will also address the time constraints of learners through the delivery of the training in a flexible and accessible way such that disruption is minimised. The training programme has an ample visual component, to cater for the needs of skill-based content. The methodological approach to training delivery is based on the Competence-based Knowledge Space Theory. Adaptive LO recommendation is time- and energy-saving, efficient and motivating as frustration (caused by over challenging LOs) and boredom (caused by unchallenging LOs) are being avoided. Although this approach is personalised, it also supports the learners within the self-regulated learning process. By developing competencies in the installation and maintenance of heat pumps, installers and maintenance personnel all over Europe will be able to leverage these capabilities in order to increase their employability in the emergent heat pump system sector. The e-training solution developed by the INNOVRET team will contribute to the development of innovative ICT-based content, services, pedagogies and practices within the context of vocational education training.

\section{ACKNOWLEDGMENT}

We thank the European Commission for funding the INNOVRET project (www.innovret.com) within the Leonardo da Vinci Transfer of Innovation Programme.

\section{REFERENCES}

[1] Council of the EU. (2011). Council conclusions on Energy 2020: A Strategy for competitive, sustainable and secure energy. [Online]. Available:

http://www.consilium.europa.eu/uedocs/cms_data/docs/pressdata/en/tr ans/119518.pdf

[2] European Commission. (2012). Europe 2020. [Online]. Available: http://ec.europa.eu/europe2020/priorities/sustainable-growth/index_en .htm

[3] EU. (2006-2013). Europe's Energy Portal. [Online]. Available: http://www.energy.eu/

[4] IEA. (2012). How heat pumps achieve energy savings and $\mathrm{CO} 2$ emissions reduction: an introduction. [Online]. Available: http://www.heatpumpcentre.org/en/aboutheatpumps/howheatpumpsac hieveenergysavings/Sidor/default.aspx

[5] Outlook 2012: European Heat Pump Statistics, European Heat Pump Association, Brussels, 2012.

[6] European Parliament, "Directive 2009/28/EC of the European Parliament and of the Council of 23 April 2009 on the promotion of the use of energy from renewable sources," Official Journal of the European Union, April 2009.

[7] European Heat Pump Statistics 2009, European Heat Pump Association, Brussels, 2010.

[8] A. Vaughan. (2010). UK heat pumps fail as green devices, finds study. The Guardian. [Online]. Available: http://www.guardian.co.uk/environment/2010/sep/08/heat-pumps-gre en-heating

[9] J. M. Barroso. (2012). Growth and jobs: Next Steps. [Online]. Available: http://ec.europa.eu/europe2020/pdf/cm012012_barroso_en.pdf

[10] EUCert - European Certified Heat Pump Installer Program, European Heat Pump Association, Brussels, 2012.

[11] Treaty on the Functioning of the European Union (title XII, articles 165 and 166), European Commission, OJC. 2008, vol. 115, p. 121.

[12] Council Conclusions of 12 May 2009 on a strategic framework for European cooperation in education and training (ET 2020), Council of the European Union, OJC. 2009, vol. 119. 
[13] C. Gravier et al., "State of the Art About Remote Laboratories Paradigms - Foundations of Ongoing Mutations," International Journal of Online Engineering, vol. 4, 2008.

[14] T. Koschmann, R. Hall, and N. Miyake, "Carrying forward the conversation," CSCL2, pp. 169-181, 2002.

[15] M. Michaelides and P. C. Eleftheriou, "Real-world experiments over the Internet: the solar energy e-learning laboratory experience," Remote Engineering and Virtual Instrumentation, 2008.

[16] C. Gravier et al., "Closing the gap between remote labs and learning management systems," in Proc. 1st International Conference on E-learning in Industrial Electronics, Tunisia, 2006, pp. 130-134.

[17] FP7-EU-funded project ROLE. [Online]. Available: www.role-project.eu

[18] FP6-EU-funded project i-Class [Online]. Available: www.iclass.info

[19] C. M. Steiner, A. Nussbaumer and D. Albert, "Supporting self-regulated learning through Competence-based Knowledge Space Theory," Policy Futures in Education, vol. 6, 2009.

[20] J. Heller et al., "Competence-based knowledge structures for personalised learning," International Journal on E-learning, vol. 5, pp. 75-88, 2006.

[21] J. P. Doignon and J. C. Falmagne, Knowledge Spaces, Berlin: Springer, 1999.

[22] J. C. Falmagne and J. P. Doignon, Learning Spaces, Berlin: Springer, 2011.

[23] R. Land et al., "Threshold concepts and troublesome knowledge (3): implications for course design and evaluation," Improving student learning: diversity and inclusivity, Oxford, OCSLD : C. Rust, 2005.

[24] K. Korossy, "Kompetenz und Performanz beim Lösen von Geometrieaufgaben", Zeitschrift für experimentelle Psychologie, vol. 43, pp. 279-318, 1996.

[25] D. Albert and J. Lukas, Knowledge spaces: Theories, empirical research and applications, Mahwah, NJ: Lawrence Erlbaum Associates, 1999.

[26] C. M. Steiner, A. Nussbaumer, and D. Albert, "Supporting self-regulated learning through Competence-based Knowledge Space Theory," Policy Futures in Education, vol. 6, 2009.

[27] Connecting learning objects to instructional design theory: A definition, a metaphor, and a taxonomy, The Instructional Use of Learning Objects: Online Version. Wiley, 2000.

[28] B. J. Zimmerman, "Becoming a Self-Regulated Learner: An Overview," Theory Into Practice, vol. 41, pp. 64-70, 2002.

[29] M. Despotovic-Zrakic et al., "Providing Adaptivity in Moodle LMS Courses," Educational Technology and Society, vol. 15, 2012.

[30] C. C. Aydin and G. Tirkes, "Open source learning management systems in e-learning and Moodle," Education Engineering (EDUCON), pp. $593-600,2010$.

[31] R. Nelson and N. Chesler, "Assessing Adaptive Expertise in Physiology Using Online Challenge Modules in Biofluids," The International Journal of Artificial Intelligence in Education, vol. 10, pp. 98-129, 2009.

[32] D. Wen et al., "Supporting Web-based Learning through Adaptive Assessment," FormaMente Journal, vol. 2, pp. 45-79, 2007.

Aurora Dimache is a research assistant at Galway-Mayo Institute of Technology (GMIT), Ireland. Currently she is involved in research activities in the development of an online solution for vocational training in heat pump systems installation. Her previous research experience lies in the areas of tools and methodologies to support SMEs in improving their sustainability, proactive engagement of SMEs with environmental issues and e-learning. Besides research and lecturing activity (face-to-face and online), Aurora worked in industry for a few years as she wanted to understand the needs of industry and the possibilities for mutually beneficial co-operation between industry and educational institutions.
Attracta Brennan is a lecturer on the Digital Media and Society Programme in GMIT Mayo. She is also adjunct lecturer at NUI Galway and Regis University, Denver, Colorado, where she is an online facilitator of the Research and Fundamental to Programming modules on the M.Sc. in Software Engineering and Database Technologies (M.Sc.S.E.D.) programme which is a distance learning programme offered jointly by NUI Galway and Regis University. Her main research interests are in pedagogy, e-learning, interactivity, graphic and instructional design.

Thomas Roche is an academic in Galway-Mayo Institute of Technology (GMIT) and has also participated in research activities in CIMRU in the National University of Ireland Galway. His research interests lie in the areas of energy management, tools and methodologies to support design engineers develop environmentally superior products, development of tools for design engineers for virtual enterprise models and e-learning tools. Dr. Thomas Roche has led, managed and delivered multi-partner national and EU research and development projects in collaboration with industry, the institute and the university. He has supervised $14 \mathrm{PhD}$ and Master students in GMIT and is the author or co-author of more than 25 journal and conference papers. In GMIT Dr. Thomas Roche has also gained experience in academic administration and college management. Hehas acted as Head of Department of Mechanical and Industrial Engineering for 3 years and has managed programs within Department.

Simone Kopeinik holds a degree in Computer Science working as a research assistant at Graz University of Technology (TUGraz). She specialized in Virtual Learning Environments with a focus on user modeling and resource recommendation. Currently working at the TUGraz - Knowledge Management Institute, she is involved in the projects INNOVRET and We SPOT. Her research interest comprises e-learning applications and tools, the use of 3D virtual worlds for learning, user adaptive and personalized (learning) systems, as well as the implementation of (psycho-)pedagogical models for user centred virtual environments.

Lisa-Christina Winter is a psychologist, working as a researcher at Graz University of Technology (TUGraz). She has been working within the European project RECOBIA (Cognitive Science Section, Knowledge Management Institute, Graz University of Technology). Her research focuses on Cognitive Bias Mitigation and its application on Intelligence Analysis.

Dietrich Albert currently acts as CSS-team-leader at Graz University of Technology (TUGraz, Knowledge Technologies Institute, Cognitive Science Section, Austria; http://kti.tugraz.at/css/), professor emeritus at University of Graz (KFUGraz, Department of Psychology, Cognitive Psychology and Neuroscience, Austria). Furthermore he is a key researcher at the Know-Center, the Austrian competence center for knowledge management. He graduated from the University of Göttingen (Germany) with a degree in psychology (Dipl.-Psychol.). His Dr.rer.nat. (D.Sc.) and his postdoctoral degree (Habilitation) he received from the University of Marburg/Lahn (Germany). He was professor of experimental psychology at the University of Heidelberg (Germany) and he chaired the Cognitive Science Section (CSS) at the Univ. of Graz from 1993 to 2010. CSS is an interdisciplinary team of psychologists, computer scientists, and mathematicians. Until recently Dietrich Albert was the Chair of the Board of Trustees of the Leibniz-Center for Psychology Information (ZPID), Germany and a member of several scientific advisory boards. His research topics cover several areas in cognitive sciences; his current research focuses on knowledge and competence structures, their applications, and empirical research - and their integration with theories of education, motivation and emotion. $\mathrm{He}$ is (co-)editor of several books, three of them on knowledge structures (published by Springer-Verlag and by Lawrence Erlbaum), and (co-)author of more than 150 publications in reviewed journals and proceedings volumes (see http://kti.tugraz.at/css/team/dietrich-albert/). 